\title{
Discovery of termitophilous tenebrionid beetles in China (Coleoptera: Tenebrionidae)
}

\author{
Ri-Xin JIANG ${ }^{1)}$, Ji-Shen $W_{A N G}^{2}$, Bo-Yan LI $^{3)}$, Ye-Jie LIN $^{4}$, Ling LIU ${ }^{5)}$ \& Shuo WANG ${ }^{1,6)}$ \\ 1) Qingdao University of Science and Technology, 53 Zhengzhou Road, Qingdao, 266042, P. R. China; e-mails: maoshuwuyouzhi@163.com; \\ shuowang@qust.edu.cn \\ ${ }^{2)}$ Key Laboratory of Plant Protection Resources and Pest Management, Ministry of Education, Entomological Museum, Northwest A\&F University, \\ Yangling, Shaanxi 712100, P. R. China \\ ${ }^{3)}$ Mingde College of Guizhou University, Siya Road, Guiyang, 550025, P. R. China; e-mail: 449116923@qq.com \\ 4) Institute of Zoology, Chinese Academy of Sciences, Beijing,100101, P. R. China \\ 5) Yunnan Academy of Forestry, Guilin, 650204, P. R. China \\ 6) corresponding author
}

Accepted:
$7^{\text {rd }}$ July 2019
Published online:
$18^{\text {th }}$ July 2019

\begin{abstract}
Two termitophilous tenebrionid genera, Nepaloplonyx Bremer, 2014 and Xenotermes Wasmann, 1896, are reported from mainland China for the first time. Nepaloplonyx yunnanensis Jiang, Wang \& Wang, sp. nov. (Yunnan Province), Nepaloplonyx qiului Jiang, Wang \& Wang, sp. nov. (Yunnan Province), and Xenotermes sp. (Yunnan Province) are described, figured and compared with their congeners. New distributional records for Ziaelas formosanus Hozawa, 1914 from Guangdong, Guangxi, Yunnan, and Jiangsu Provinces are provided. Biological information, collection data and distribution map of all four species are also provided.
\end{abstract}

Key words. Coleoptera, Tenebrionidae, Amarygmini, Rhysopaussini, new species, new records, termitophily, Odontotermes, fungus garden, China

Zoobank: http://zoobank.org/urn:lsid:zoobank.org:pub:0B329EFD-A84C-4034-AA77-C1D373370F5A

(C) 2019 The Authors. This work is licensed under the Creative Commons Attribution-NonCommercial-NoDerivs 3.0 Licence.

\section{Introduction}

The termitophilous habit is reported in the following Oriental tenebrionid genera: Nepaloplonyx Bremer, 2014(2 spp., tribe Amarygmini), Xenotermes Wasmann, 1896 (1 sp., tribe Rhysopaussini), and Ziaelas Fairmaire, 1892 (3 spp., tribe Amarygmini). Members of these three genera inhabit termite nests and can be usually found in the fungus garden of the termites (WASMANN 1896, HozaWA 1914, BREMER 2013). Most termitophilous tenebrionid beetles of the tribes Amarygmini and Rhysopaussini were recently catalogized by Bremer \& Lillig (2014). To date, Ziaelas formosanus Hozawa, 1914 from Taiwan and Fujian Provinces is the only termitophilous tenebrionid beetle known from China.

The genus Nepaloplonyx Bremer, 2014 was established for Nepaloplonyx caelebs Bremer, 2014 from Nepal. The second known species, N. singularis (Wasmann, 1896) from northeast India, was transferred to Nepalonyx from Azarelius Fairmaire, 1892 based on unarmed profemora (BERMER 2014).
The monotypic genus Xenotermes Wasmann, 1896, with Xenotermes feai Wasmann, 1896 from Myanmar and Thailand, was placed in the tribe Rhysopaussini. Historically, the tribe Rhysopaussini was devised as the family Rhysopaussidae near the families Paussidae (presently Paussinae, Carabidae) and Rhysodidae (presently Rhysodini, Carabidae; WASMANN 1896). Later on, it was regarded as the subfamily Rhysopaussinae in Tenebrionidae (Wasmann 1912). Then, it was downgraded to the tribe Rhysopaussini (Tenebrioninae) and hypothesized to stand near Amarygmini (GeBIEN 1943).

The genus Ziaelas Fairmaire, 1892 was established with Ziaelas insolitus Fairmaire, 1892 from Vietnam as the type species, and a second species, Z. formosanus, was later reported from Taiwan, China (Hoozawa 1914). Recently, Z. fujiokai Masumoto, Lee and Akita, 2016 was described from Vietnam, and it was compared with $Z$. formosanus, which was confirmed to be a well-delimited species (Матsumoto et al. 2016). 
In this paper, we report the first discovery of the genera Nepaloplonyx and Xenotermes from China with descriptions of Nepaloplonyx yunnanensis sp. nov., Nepaloplonyx qiului sp. nov., and Xenotermes sp. from Yunnan Province. New distributional records of Z. formosanus from Guangdong, Guangxi, Yunnan, and Jiangsu Provinces, China are also provided. The termitophilous tenebrionid beetles from China are herein summarized, with their biological information, collection data, and their distributions provided.

\section{Material and methods}

Materials examined in this study are deposited in the following collections:

CWIC Wen-I Chou Collection, Taiwan, China;

GUGC Insect Collection of the Institute of Entomology, Guizhou University, Guizhou, China (Bo-Yan Li);

IZAS Institute of Zoology, Chinese Academy of Science, Beijing, China;

JQYC Quan-Yu Ji Collection, Jiangsu, China;

LYJC Yie-Jie Lin Collection, Liaoning, China;

MHBU Museum of Hebei University, Hebei University, Baoding, China (Xing-Long Bai);

NMPC National Museum, Prague, Czech Republic (Jiří Hájek);

QLC Lu Qiu Collection, Chongqing, China;

QUST Insect Collection of Qingdao University of Science and Technology, Qingdao, China (Ri-Xin Jiang);

TZYC Zhao-Yang Tang Collection, Guangdong, China;

YNAF Insect Collection of the Yunnan Academy of Forestry, Kunming, China (Ling Liu).

The collecting data of the material are quoted verbatim. The Chinese translation of each locality below provincial level is included in parentheses at the first appearance in the text. Each type specimen bears the following label: 'HOLOTYPE (red) or PARATYPE (yellow), ô or + , generic name + specific name sp. nov., det. Jiang, Wang \& Wang 2019.'.

Habitus images were taken using a Canon 5D SR camera with a MP-E $65 \mathrm{~mm} \mathrm{f} / 2.81-5 \mathrm{X}$ macro lens (Figs. 1-7, 13-18, 22-27, 31-33). A Canon MT-26EX twin flash was used as the light source. Images of the morphological details were made using a Canon G9 camera mounted on an Olympus CX31 microscope under transmission lights (Figs 8-12, 28-30, 34-37) or a Canon 5D SR camera with a Mitutoyo Plan NIR 10 lens (Figs 19-21). Zerene Stacker (version 1.04) was used for image stacking. All images were modified and grouped into plates in Adobe Photoshop CS5 Extended. The distribution map (Fig. 46) was downloaded from SimpleMappr (www.simplemappr. net), and modified in Adobe Photoshop CS5 with added species records.

The following acronyms are applied:

$\begin{array}{ll}\text { AL } & \text { length of aedeagus; } \\ \text { AnL } & \text { length of antenna; } \\ \text { BL } & \text { body length from anterior margin of clypeus to apex of elytra; } \\ \text { EL } & \text { length of elytra along suture; } \\ \text { EW } & \text { maximum width of elytra; } \\ \text { HL } & \text { length of head from anterior clypeal margin to occipital con- } \\ & \text { striction; } \\ \text { HW } & \text { width of head across eyes; } \\ \text { PL } & \text { length of pronotum along midline; } \\ \text { PW } & \text { maximum width of pronotum including lateral teeth. }\end{array}$

\section{Descriptions of new species}

\author{
Nepaloplonyx yunnanensis \\ Jiang, Wang \& Wang, sp. nov. \\ (Figs 1-12, 40)
}

Type material (19 exs). Ноцотуре: $\widehat{\jmath}$, labeled: 'China: Yunnan, Jinping County (金平县), Ganxiao Village (干校村), $22^{\circ} 36^{\prime} 17^{\prime \prime} \mathrm{N}, 103^{\circ} 09^{\prime} 54^{\prime \prime} \mathrm{E}$, 2018.04.20, H: 300 m, termite nest, Li Yun-Xing leg.' (GUGC). PARATYPES $(10$ of 5 우): 9 o 우, labeled: 'China: Yunnan, Wenshan Prefecture (文山州), Malipo County (麻栗坡县), $23^{\circ} 09^{\prime} 87^{\prime \prime} \mathrm{N}, 104^{\circ} 40^{\prime} 63^{\prime \prime} \mathrm{E}$, 2018.06.04, H: 1100 m, light trap.' (4 के 2 웅 MHBU, 5 के 2 우 GUGC); 1 , labeled: '2010.VII.25, Yunnan, Shuifu (水富县), Taiping, 800 m, Xu Ji-Shan leg.' (MHBU); 1 , , labeled: 'Yunnan, Xishuangbanna (西双版纳), Mengla (预腊), 620-650m, 1959.VI.7, Li Suo-Fu leg, IOZ(E), 965663' (IZAS). 3 exs, labeled: 'China: Yunnan, Yingjiang County (盈江县), Nabang Town (那邦镇), H: 252 m, 4-VI-2018, Lu Qiu leg., Light trap' (2 exs QLC, 1 ex. MHBU).

Description. Male (Figs 1-2). Body dark brown, dorsal surface weakly flattened.

Head (Figs 3-5) wider than long, vertex strongly punctured behind compound eyes. Head capsule deeply concave before compound eyes and around base of antennae, and forming greatly raised Y-shaped ridge frontally. Compound eyes short, separated medially. Clypeus (Fig. 5) relatively large and vertical, unobservable in dorsal view, smooth, and slightly emarginate at apical margin. Labrum (Fig. 5) narrower than clypeus, smooth, nearly trapezoidal, covered with bristles of medium length in apical portion. Antennae (Fig. 7) short when compared to non-termitophilous Amarygmini, and antennomeres strongly expanded, with 11 antennomeres; antennomere I longest, longer than wide; II shortest, wider than long; III spherical, slightly longer than wide; IV-XI wider than long, strongly expanded; XI narrower than preceding ones with rounded apex.

Pronotum (Figs 3-4) approximately as long as wide, rough surface covered with big punctures, with two pairs of strong ridges; inner ridges straight, equal to approximately $3 / 4$ of pronotal length and not extending to hind border of pronotum, outer ridges curved medially, extending from hind border to nearly anterior border of pronotum; lateral margin curved, widest near middle, with right-angled hind corners. Elytra elongate, sides subparallel; intervals II-IX keel-shaped; II-VIII unconnected with elytral apex; IV shortest, nearly $2 / 3$ of elytral length; $\mathrm{V}$ approximately $5 / 6$ of elytral length; III connected or disconnected with VI apically. Femora glabrous in shaft area; profemora (Fig. 6) bluntly projected near apex. Tibiae with two edges on outer side, and two long bristles and circle of short bristles at apex. Aedeagus (Figs 8-10) simple and slender, subfusiform, curved in lateral view, with asymmetrical base.

Measurements. AnL 3.89-3.98 mm, BL 7.26-7.50 mm, HL 0.81-0.83 mm, HW 1.01-1.04 mm, PL $1.67-1.71 \mathrm{~mm}$, PW 1.61-1.66 mm, EL 4.78-4.96 mm, EW 2.29-2.32 mm, AL $1.47 \mathrm{~mm}$. Ratio of AnL for each antennomere from basal to apical (holotype): $0.58,0.19,0.32,0.26,0.26$, $0.24,0.24,0.24,0.24,0.22,0.27$.

Female. Similar to males, but slightly larger, without obvious sexual dimorphism. Sternite VIII (Fig. 12) semicircular, deeply split medially at posterior margin, 
and covered with dense long setae. Spiculum (Fig. 12) tortuous in middle. Apex of ovipositor (Fig. 11) with one long seta.

Measurements. BL 8.17-8.57 mm, HL 0.96-0.99, HW 1.07-1.09 mm, PL 1.80-1.86 mm, PW 1.67-1.74 mm, EL 5.38-5.75 mm, EW 2.25-2.32 mm, Anl 2.62-2.70 $\mathrm{mm}$.

Comparative notes. The new species is similar to $\mathrm{Ne}$ paloplonyx caelebs Bremer, 2014 in its general appearance, especially strongly expanded antenna, but can be easily separated from the latter by subapically projected profemora, and different pattern of the outer ridges on the pronotum.

Etymology. The specific epithet refers to the type locality, Yunnan Province; adjective.

Biology. The new species lives in the nest of the termite Odontotermes sp. The specimens were mostly collected from the fungus garden of the termites (Fig. 40) and also caught by the light trap.

Distribution. China: Yunnan (Fig. 46).
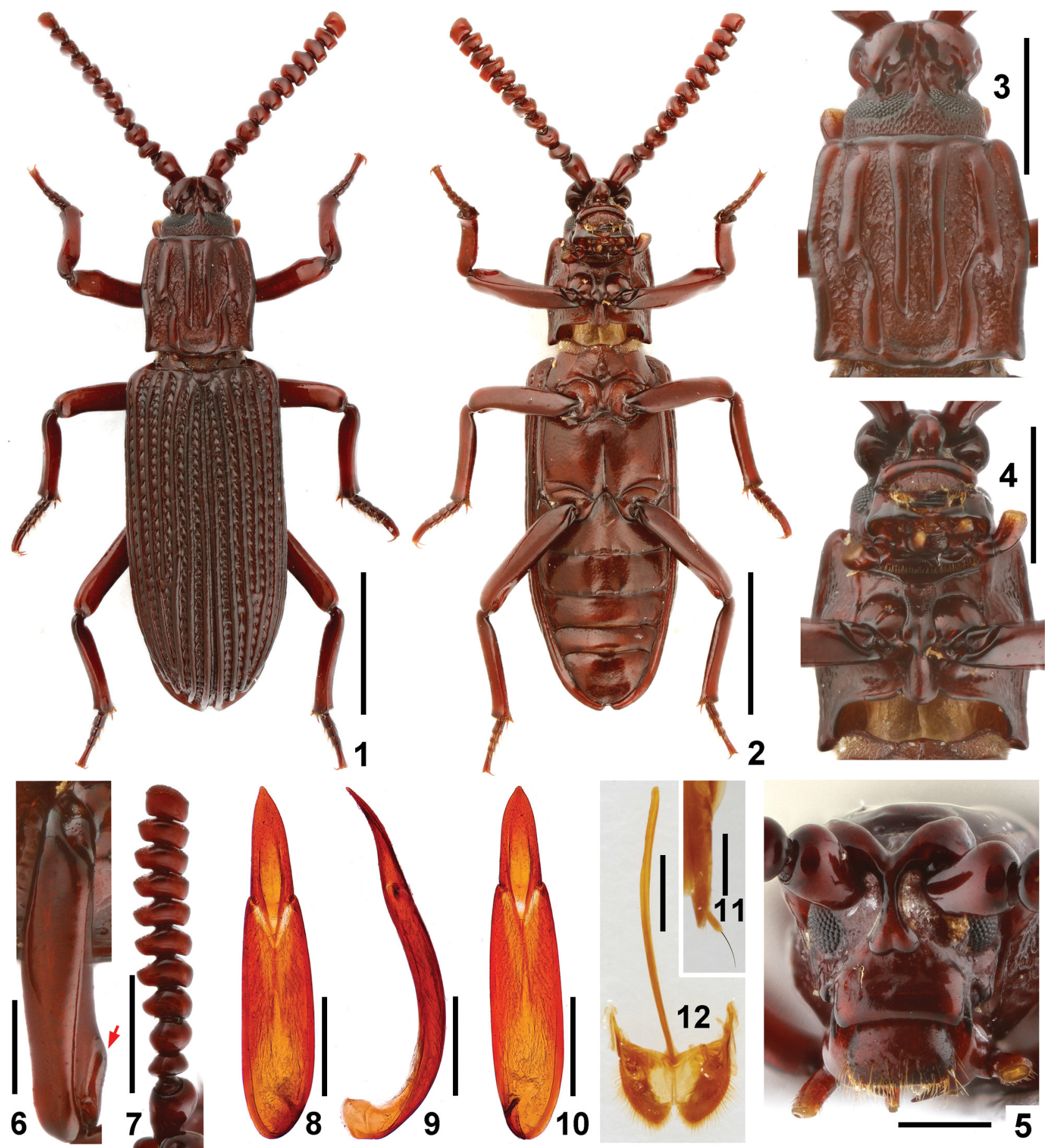

Figs 1-12. Diagnostic features of Nepaloplonyx yunnanensis sp. nov. (1-10 - male; 11-12 - female). 1 - habitus dorsal view; 2 - habitus ventral view; 3-4 - head and prothorax, dorsal and ventral views, respectively; 5 - head, frontal view; 6 - profemur, ventral view; 7 - antenna, lateral view; 8-10 aedeagus, dorsal, lateral and ventral views; 11 - apex of ovipositor, ventral view; 12 - sternite VIII and spiculum, ventral view. Scale bars: 2.0 mm in Figs 1-2; $1.0 \mathrm{~mm}$ in Figs 3-4, 7; $0.5 \mathrm{~mm}$ in Figs 5-6, 12; $0.4 \mathrm{~mm}$ in Figs 8-10; and 0.25 mm in Fig. 11. 


\section{Nepaloplonyx qiului Jiang, Wang \& Wang, sp. nov.}

(Figs 13-21, 44)

Type material (1 ex.). HoLoTYPE: 3 , labeled: 'China: Yunnan, Yingjiang County (盈江县), Nabang Town (那邦镇), H: 252 m, 4-VI-2018, Lu Qiu leg., Light trap' (MHBU).

Description. Male (Figs 13-14). Body dark brown, dorsal surface weakly flattened and covered with well-distributed and dense tiny punctures.

Head (Figs 15-17) wider than long, vertex strongly punctured at base of area behind compound eyes. Head capsule deeply concave before compound eyes and around base of antennae, and forming greatly raised Y-shaped ridge frontally. Compound eyes short, separated medially. Clypeus (Fig. 17) relatively large and vertical, unobservable in dorsal view, smooth, and slightly emarginate at apical margin. Labrum (Fig. 17) narrower than clypeus, smooth, nearly trapezoidal, covered with bristles of medium length on apical portion, bristles on middle part shorter than on other parts. Antennae (Fig. 18) short when compared to non-termitophilous Amarygmini, and antennomeres
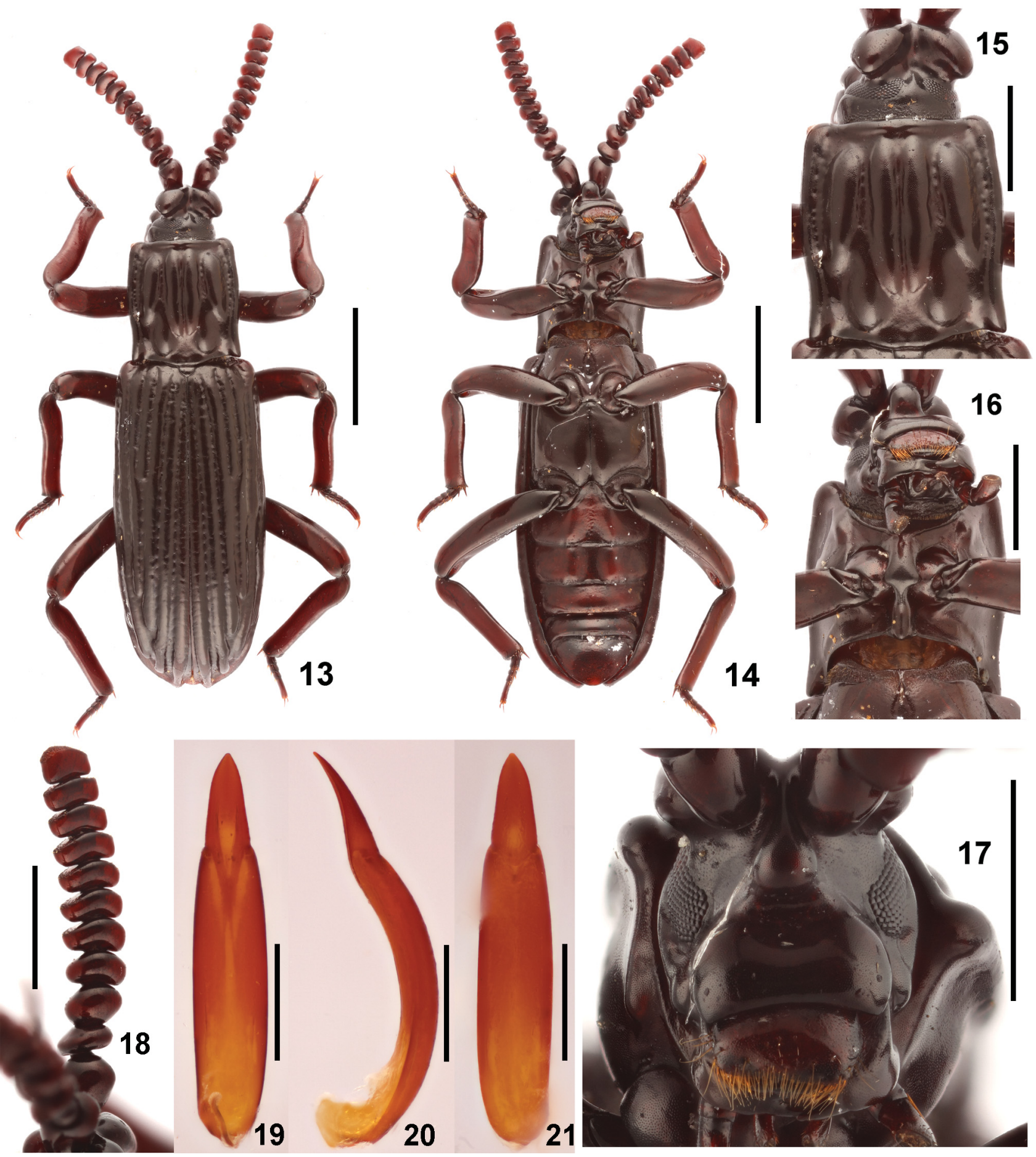

Figs 13-21. Diagnostic features of Nepaloplonyx qiului sp. nov. 13 - habitus of male, dorsal view; 14 - habitus of male ventral view; $15-16$ - head and prothorax, dorsal and ventral views, respectively; 17 - head, frontal view; 18 - antenna, lateral view; 19-21 - aedeagus, ventral, lateral and dorsal views. Scale bars: $2 \mathrm{~mm}$ in Figs 13-14, $1.0 \mathrm{~mm}$ in Figs 15-18; $0.5 \mathrm{~mm}$ in Figs 19-21. 
strongly expanded, with 11 antennomeres; antennomere I longest, longer than wide; II short, wider than long; III spherical, wider than long; IV-XI wider than long, strongly expanded; X shortest; XI narrower than preceding ones, with rounded apex.

Pronotum (Figs 15-16) longer than wide, shiny surface covered with dense tiny punctures, with two pairs of broad and strong ridges; inner ridges straight, equal to approximately $3 / 4$ of pronotal length and not extending to hind border of pronotum, outer ridges discontinuous medially, extending from hind border to nearly anterior border of pronotum; lateral margin curved, widest near middle, with right-angled hind corners. Elytra elongate, sides subparallel; intervals strong and broad, intervals IIV straight; V-IX keel-shaped; II-VIII unconnected with elytral apex; IV shortest, nearly $1 / 3$ of elytral length; V approximately $3 / 4$ of elytral length. Femora glabrous in shaft area; profemora without modification. Tibiae with two edges on outer side, and two long bristles and circle of short bristles at apex. Aedeagus (Figs 19-21) simple and slender, subfusiform, curved in lateral view, with asymmetrical base.

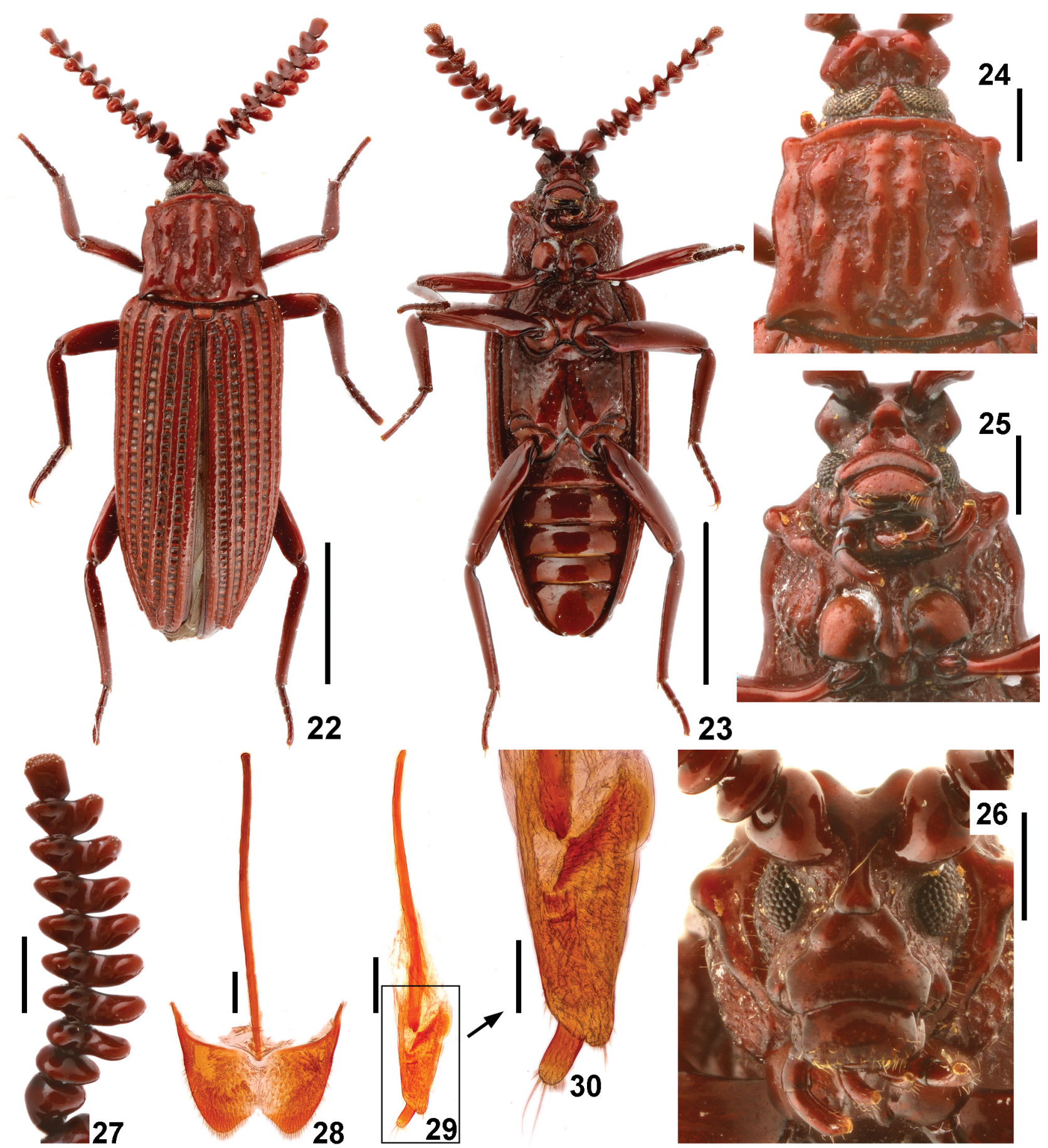

Figs 22-30. Diagnostic features of female of Xenotermes sp. from Lincang City, Yunnan. 22 - habitus, dorsal view; 23 - habitus, ventral view; 24-25 head and prothorax, dorsal and ventral views, respectively; 26 - head, frontal view; 27 - antenna, lateral view; 28 - sternite VIII and spiculum, ventral and lateral views, respectively; 29-30 - apex of ovipostor, ventral view. Scale bars: 2 mm in Figs 22-23; 0.5 mm in Figs 24-27; 0.2 mm in Figs 28-29; and $0.1 \mathrm{~mm}$ in Fig. 30 . 
Measurements: AnL 3.13 mm, BL $9.50 \mathrm{~mm}$, HL 0.98 mm, HW 1.24 mm, PL 2.18 mm, PW 1.95 mm, EL 6.34 $\mathrm{mm}$, EW $2.50 \mathrm{~mm}$, AL $1.70 \mathrm{~mm}$. Ratio of AnL for each antennomere from basal to apical (holotype): 0.61, 0.22, $0.33,0.27,0.23,0.23,0.23,0.23,0.23,0.21,0.29$.

Female. Unknown.

Comparative notes. The new species can be easily separated from other Nepaloplonyx species by strong and broad ridges on pronotum and intervals on elytra.

Etymology. This species is named in honor of our friend Dr. Lu Qiu, who collected the new species and donated it to us for study.

Biology. The holotype was caught by the light trap (Figs 43-45). Discovery of its termitophilous habit is highly expected in future works.

Distribution. China: Yunnan (Fig. 46).

\section{New distributional records}

\section{Xenotermes sp. \\ (Figs 22-30, 42)}

Material examined (1 ex.). + , labeled: 'China: Yunnan Prov., Lincang City (临沧市), Yongde County (永德县), Yalian Township (亚练乡), $24^{\circ} 14^{\prime} 03^{\prime \prime} \mathrm{N}, 99^{\circ} 56^{\prime} 49^{\prime \prime} \mathrm{E}, 2015$. VIII.22, $1410 \mathrm{~m}$, Light trap, Wang Ji-Shen leg.' (LYJC).

Description. Female (Figs 22-23). Body reddish brown, dorsal surface weakly flattened.

Head (Figs 24-26) strongly wider than long, vertex punctured behind compound eyes. Head capsule deeply concave before compound eyes and around base of antennae, and forming raised Y-shaped ridge frontally. Compound eyes longitudinally short, separated dorsally. Clypeus (Fig. 26) relatively large and vertical, unobservable in dorsal view, smooth, and slightly emarginate at apical margin. Labrum (Fig. 26) narrower than clypeus, smooth, nearly rectangular, covered with short bristles on apical portion. Antennae (Fig. 27) short, antennomeres strongly expanded and asymmetrical, with 10 antennomeres. Antennomere I longest, slightly longer than wide; II shortest, wider than long; III-IX strongly expanded and asymmetrical, with dorsal portion nearly twice as wide as ventral; $\mathrm{X}$ markedly narrower than IX, with rounded apex.

Pronotum (Figs 24-25) slightly wider than long, trapezoidal, surface rough and covered with sparse short setae. Lateral margin wavy, widest at base, strongly pointed at hind corners. Pronotum with two pairs of strong ridges; inner ridges straight, equal to approximately $3 / 4$ of pronotal length and not extending to hind border of pronotum; outer ridges discontinuous in middle, extending from hind border of pronotum to nearly anterior border; Elytra elongate, sides subparallel; interval IV shortest, approximately $4 / 5$ of elytral length; III approximately $6 / 7$ of elytral length. Legs simple, tibiae slightly tapering towards apex.

Sternite VIII (Fig. 28) semicircular, deeply split medially at posterior margin with dense long setae. Spiculum (Fig. 28) tortuous in middle. Apex of ovipositor (Figs 29-30) with two long setae.
Measurements. BL $6.67 \mathrm{~mm}$, HL $0.57 \mathrm{~mm}$, HW 0.94 mm, AnL 2.63 mm, PL 1.54 mm, PW 1.78 mm, EL 4.56 $\mathrm{mm}$, EW $2.28 \mathrm{~mm}$. Ratio of AnL for each antennomere from basal to apical: $0.44,0.20,0.22,0.24,0.24,0.24$, $0.24,0.24,0.24,0.28$.

Male. Unknown.

Comparative notes. The specimen in this study resembles Xenotermes feai Wasmann, 1896 from Myanmar and Thailand in the general appearance, but has different shape of the pronotum, especially the strongly pointed hind corners. However, due to the male being unknown, we herein report this female specimen as Xenotermes sp. Biology. The female specimen was collected by the light trap (Fig. 42). Discovery of its termitophilous habit is highly expected in future works.

Distribution. China: Yunnan (Fig. 46).

\section{Ziaelas formosanus Hozawa, 1914}

(Figs 31-37, 41)

Ziaelas formosanus Hozawa, 1914: 484, pl. VI. Type locality: Kuraru, Ako District, Formosa [=Sheding (社顶), Hengchun Town (恒春镇), Pingdong County (屏东县), Taiwan, China].

Material examined (33 exs). CHINA: Gungdong: 8 of 9 우, labeled: 'China: Guangdong Prov., Shenzhen City (深圳市), Shenzhen Institute of Technology (深圳技师学院), Light trap, H: 30 m,

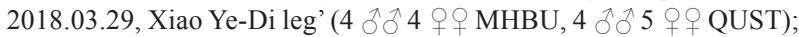
5 exs, labeled: 'Guangdong, Shaoguan City (韶关市), Shixing County (始兴县), 2018. 08.29, Lu Rui-Hua leg., in fungus garden of Odontotermes sp.' (GUGC); 2 exs, labeled: 'China: Guangdong Prov, Shenzhen City (深圳市), Getian Village (各田村), 2019.05.15, Zhao-Yang Tang \& Bao-Ping Huang leg., Light trap' (TZYC). Guangxi: 1 ex., labeled: 'China, Guangxi A.R., Shiwandashan National Forest Park, (forested river valley; at light), $21^{\circ} 54.4^{\prime} \mathrm{N}, 17^{\circ} 54.2^{\prime} \mathrm{E}, 290-360 \mathrm{~m}, 5 .-9$. iv.2013, M. Fikáček, J. Hájek \& J. Růžžčka leg.'(NMPC). Yunnan: 6 exs, labeled: 'Yunnan, Chuxiong (楚雄), Yong'ren (永仁), 2018.07.09, collect by attractant reagent' (YAOF). JiAngSu: 1 ex., labeled 'China: Jiangsu, Zhenjiang City (镇江市), Jingkou District (京口区), Jiangsu University (江苏大学), H: 10 m, 2-X-2018, Quan-Yu Ji leg.' (JQYC). TaIwan: 1 ex., labeled: 'China: Taiwan, Pingdong County (屏东县), Wutai Township (雾台乡), Wu tai (雾台), H: 1000 m, 6-VI-2019, Wen I Chou leg., Light trap' (CWIC).

Supplementary description. Male. Habitus and aedeagus as shown in Figs 31-35.

Female. Similar to males, without obvious sexual dimorphism. Sternite VIII (Fig. 36) semicircular, deeply split medially at posterior margin, with dense, long setae. Spiculum (Fig. 36) tortuous in middle. Apex of ovipositor (Fig. 37) with one long hair.

Measurements. BL 7.28-8.31 mm, HL 0.74-0.83, HW 0.98-1.07 mm, PL 1.54-1.81 mm, PW 1.55-1.85 mm, EL 5.00-5.67 mm, EW 2.17-2.22 mm, Anl 2.84-2.89 mm.

Biology. Ziaelas formosanus Hozawa, 1914 lives in the nest of the termite Odontotermes sp. and was found in the fungus garden of Odontotermes sp. (Fig. 41). The adults can also be caught by the light trap.

Distribution. China: Guangdong, Guangxi, Yunnan, Fujian, Jiangsu and Taiwan (Fig. 46).

Comments. Ziaelas formosanus was originally described from Taiwan and Mazu Island (Fujian Province), China, and is herein newly recorded from mainland China (Guangdong, Guangxi, Yunnan, and Jiangsu Provinces). The extrenal morphology and genitalia of the above speci- 


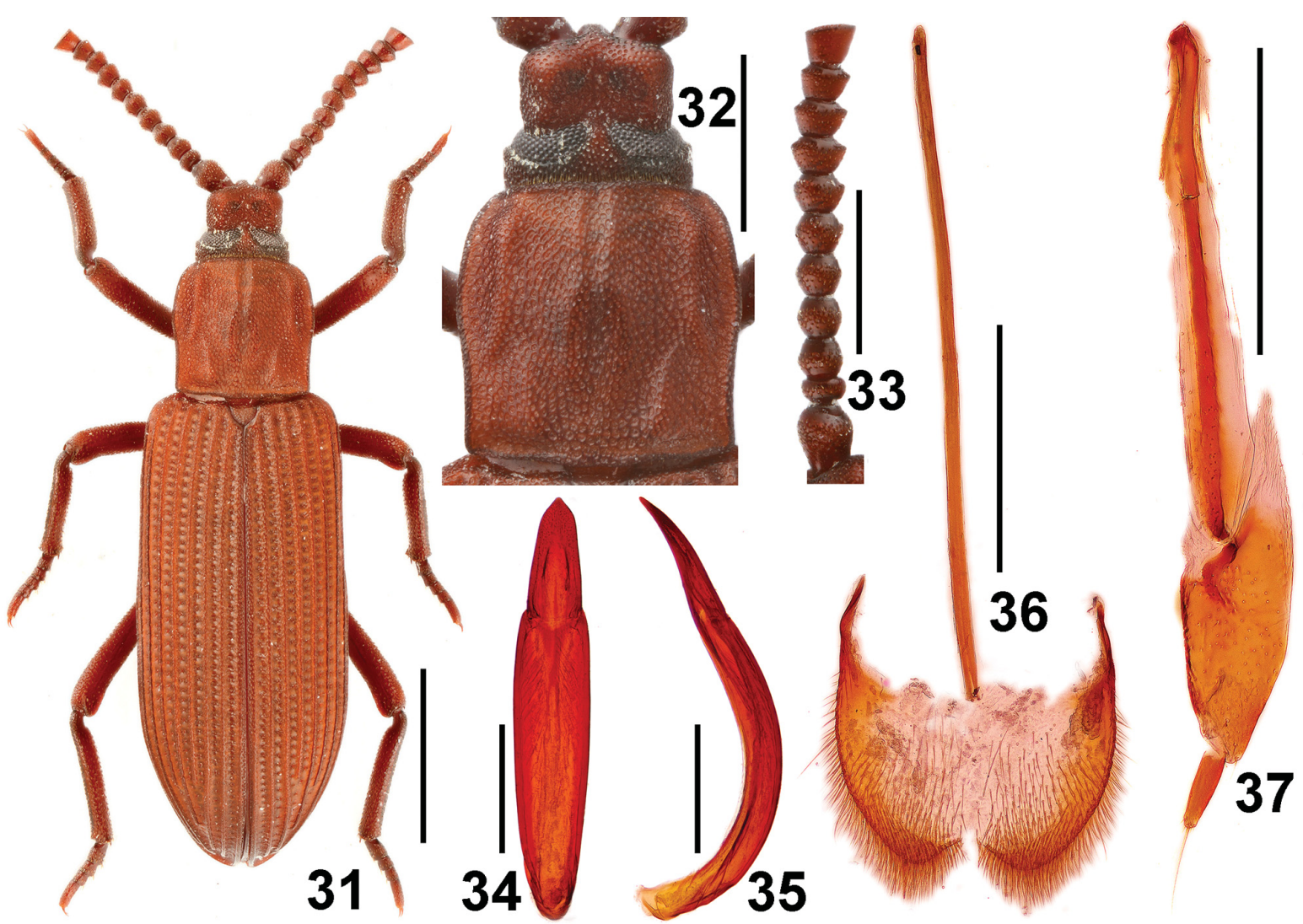

Figs 31-37. Ziaelas formosanus Hozawa, 1914 (31-35 - male, 36-37 - female). 31 - habitus, dorsal view; 32 - head and prothorax, dorsal view; 33 antenna, lateral view; 34-35 - aedeagus, dorsal and lateral views, respectively; 36 - sternite VIII and spiculum, ventral view; 37 - ovipositor, ventral view. Scale bars: $2.0 \mathrm{~mm}$ in $31,1.0 \mathrm{~mm}$ in $32-33$; and $0.5 \mathrm{~mm}$ in $34-37$.
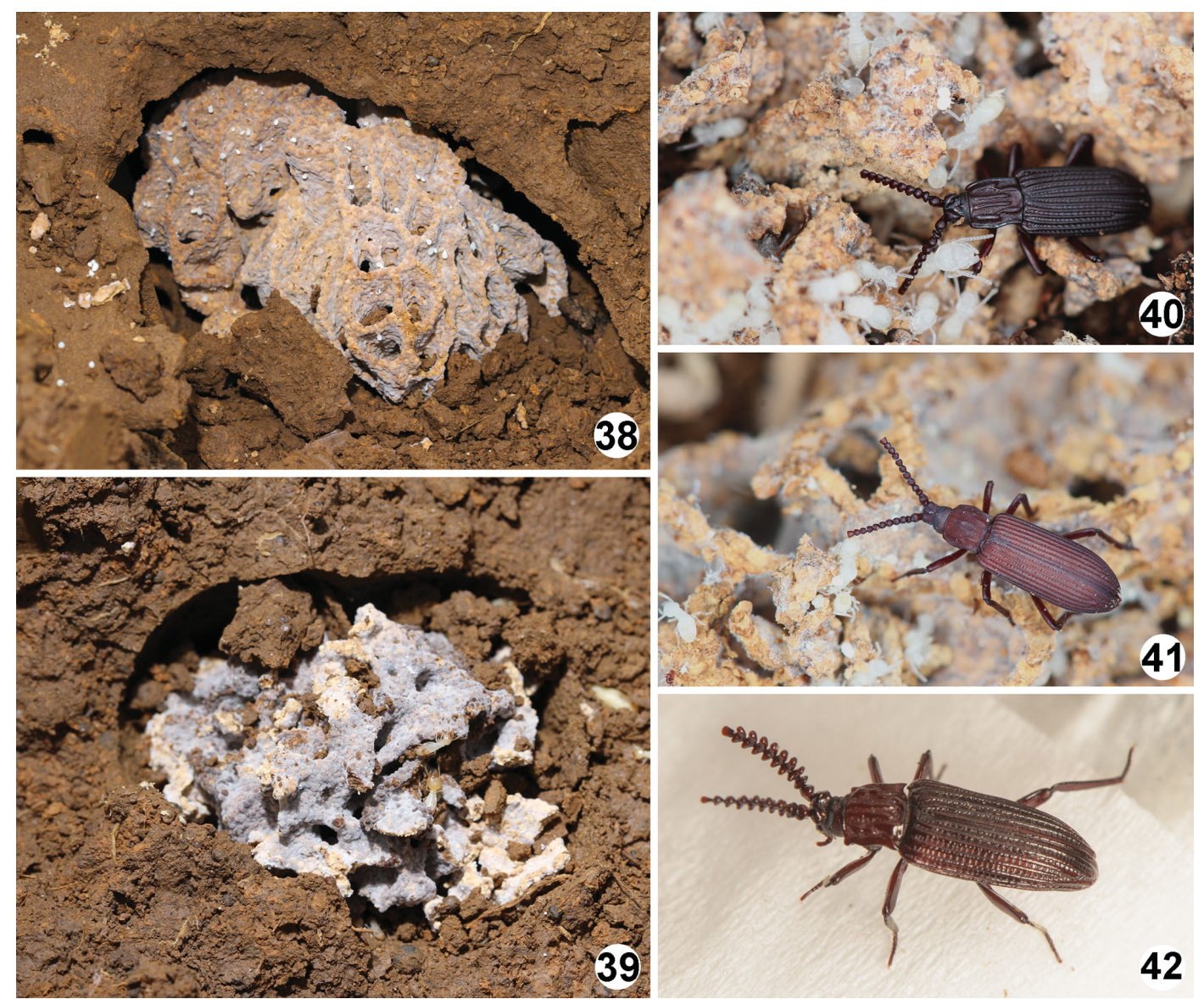

Figs 38-42. Habitat of termitophilous tenebrionid beetles. 38-39 - fungus garden of Odontotermes sp., 30 - male of Nepaloplonyx yunnanensis sp. nov. on fungus garden; 41 - male of Ziaelas formosanus Hozawa, 1914 on fungus garden; 42 - female of Xenotermes sp. trapped at light. 

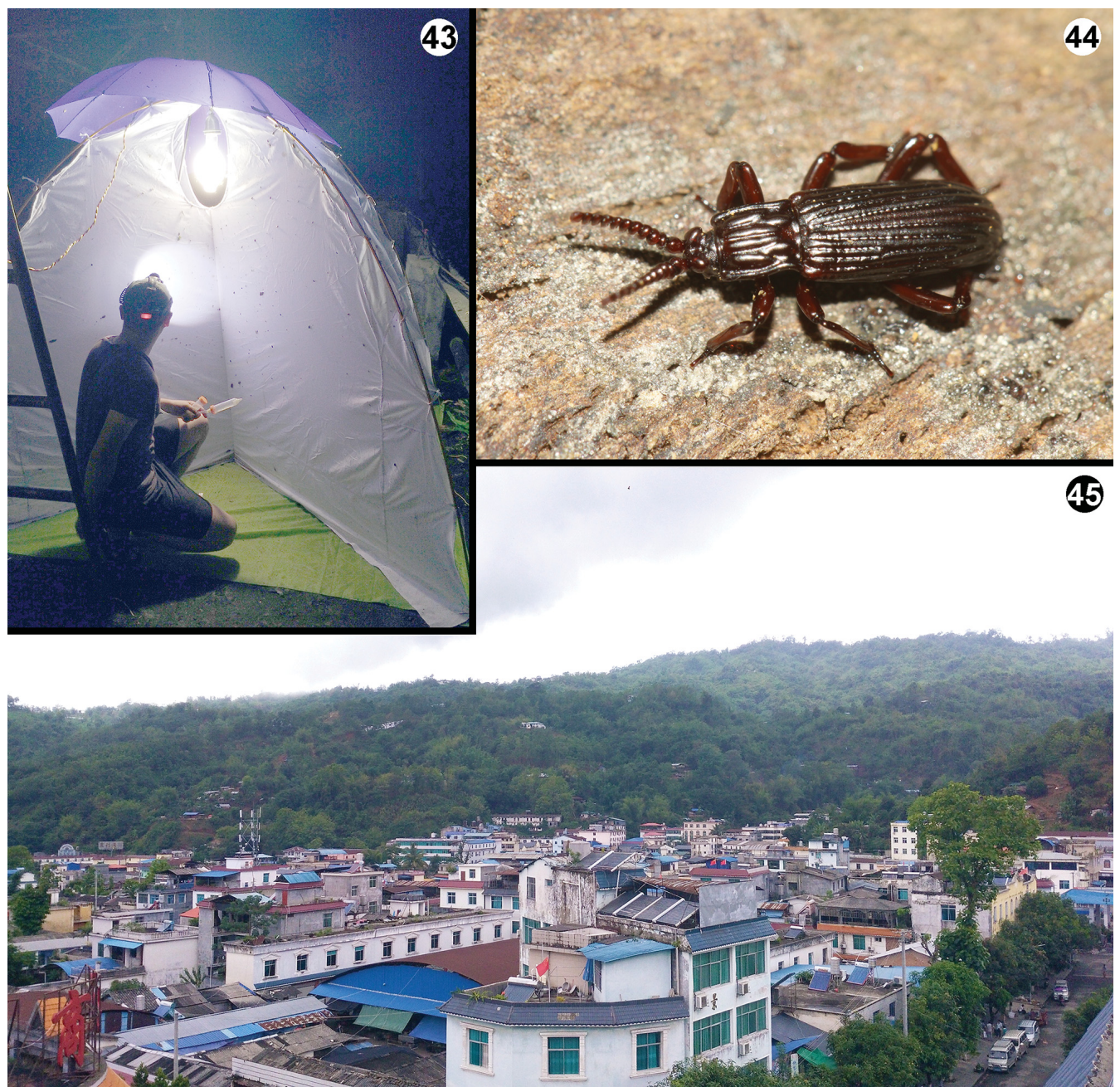

Figs 43-45. Habitat of Nepaloplonyx qiului sp. nov. 43 - Dr. Lu Qiu working at the light trap in the type locality: Nabang Town (Yingjiang County, Yunnan Province); 44 - holotype of $N$. qiului sp. nov. trapped at light; 45 - general environment of Nabang Town.

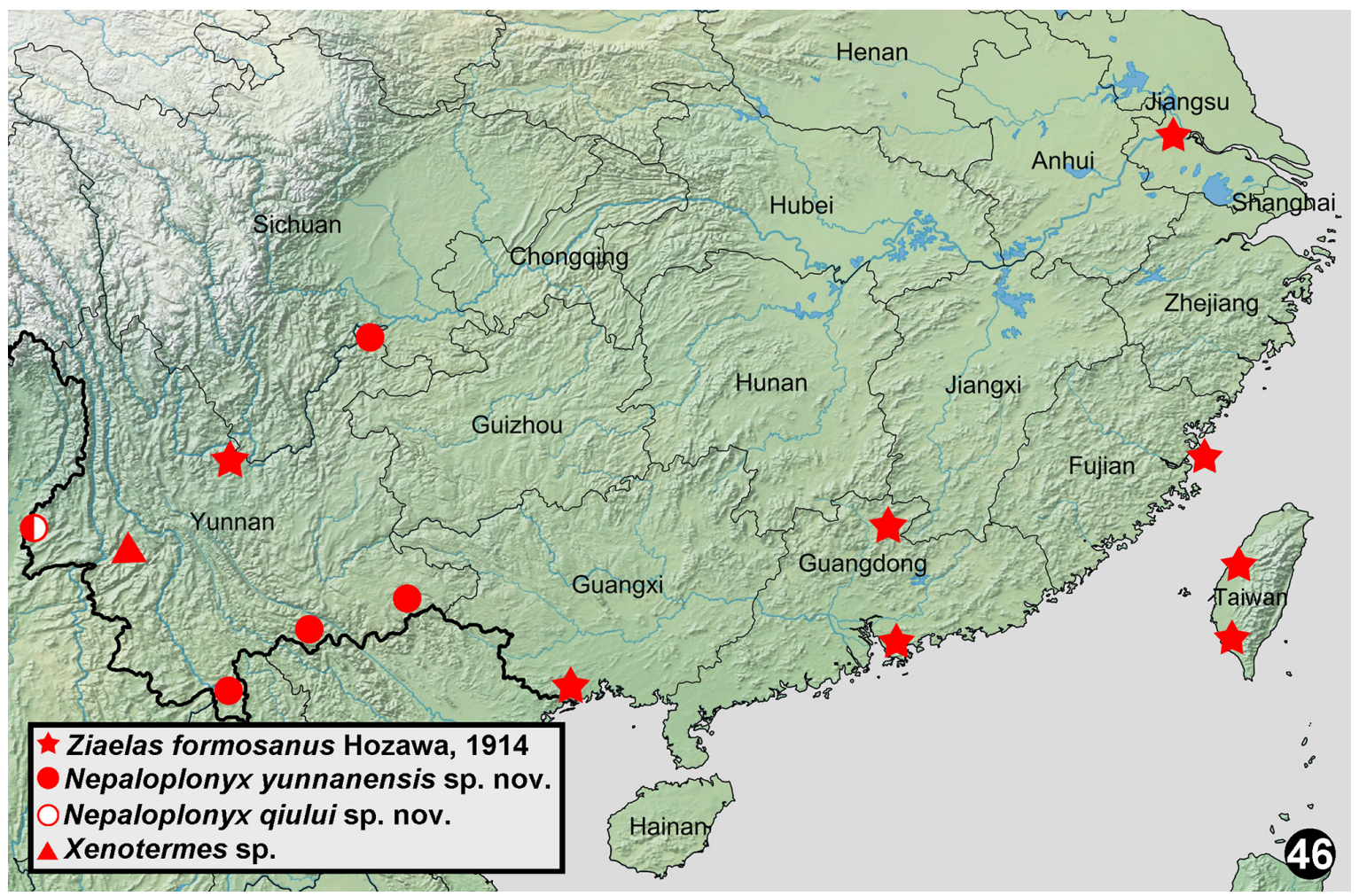

Fig. 46 Distribution of termitophilous tenebrionid beetles known from China. 
mens correspond with those of $Z$. formosanus as illustrated by Matsumoto et al. (2016), and we hence consider the specimens from the mainland conspecific.

\section{Discussion}

Bremer (2014) established the genus Nepaloplonyx, and transferred Azarelius singularis Wasmann, 1896 into Nepaloplonyx on account of unarmed profemora. Therefore, the genus Azarelius Fairmaire, 1892 consists of six species, and all of them possess spined profemora. The new species Nepaloplonyx yunnanensis sp. nov. lacks the spine, but has profemur bluntly projecting in the same position. This projection may represent a transition phase between the character states found in Nepaloplonyx and Azarelius. Otherwise, all known species of Azarelius (except $A$. oberthueri Wasmann, 1896) have a very short interval IV on the elytra, while Nepaloplonyx members possess a much longer one. The relatively long interval IV is also observed in N. yunnanensis sp. nov. Similar situation can also be found in $N$. qiului sp. nov. which has unarmed protibia and a relatively short interval III on the elytra. For the above reasons, $N$. yunnanensis sp. nov. and $N$. qiului sp. nov. are placed in the genus Nepaloplonyx. Further research is needed to shed more light on the relationship of these two genera.

Thus far, these three genera have only been found to cohabit with Odontotermes termites. The adults are ignored by the termites and free from their attack, while the immature stages are still unknown. It is not easy to find the fungus gardens in the nests of Odontotermes sp. (Figs 38-39 ) since they are usually built deep in the soil. Therefore, the termitophilous tenebrionid beetles are difficult to collect from the underground. However, there are other effective collecting means, such as using light traps or broad-spectrum attractant agentia. In fact, most specimens of $Z$. formosanus in this study were collected by a young insect fan under the street light, in the school yard of an urban area, Shenzhen City, Guangdong, China.

\section{Acknowledgments}

We would like to express our sincere gratitude to $\mathrm{Mr}$. Ming-Zhi Zhao, Mr. Zhao-Yang Tang, and Mr. Ye-Di Xiao (Guangdong, China), Dr. Xing-Long Bai (Hebei,
China), Mr. Quan-Yu Ji (Jiangsu, China), and Dr. Wen I Chou (Taiwan, China) for providing some materials, to Dr. Martin Lillig (Saarbrücken, Germany) and Dr. Wolfgang Schawaller (Stuttgart, Germany) for providing references, and to Dr Cheng-bin Wang (Sichuan, China) and Mr. Peng Wang (Yunnan, China) for their support of our work. We are also grateful to Dr. Martin Fikáček (Prague, Czechia) for his guidance in this work. Our thanks also go to Dr. Hans Bremer (Osnabrück, Germany), Dr. Jiř́ Hájek (Prague, Czechia), and one anonymous reviewer for giving us constructive suggestions; Jiří Hájek and Martin Fikáček also provided information of Ziaelas formosanus from Guangxi, China. This research was supported by the National Natural Science Foundation of China (Grant No. 31801022) and the Scientific Research Start-up Foundation of Qingdao University of Science and Technology (Grant No. 0100229021).

\section{References}

BREMER H. J. 2013: Annotations on the tribe Rhysopaussini and on some genera assigned to this tribe (Coleoptera: Tenebrionidae: Rhysopaussini: Amarygmini). Mitteilungen der Münchner Entomologischen Gesellschaft 103: 71-79.

BREMER H. J. 2014: Revision of Azarelius Fairmaire, Ziaelas Fairmaire and related Oriental termitophilous genera, with descriptions of two new genera and remarks on tribal placement (Coleoptera: Tenebrionidae: Amarygmini). Stuttgarter Beiträge zur Naturkunde A, Neue Serie 7: 163-182.

BREMER H. J. \& LILLIG M. 2014: World catalogue of Amarygmini, Rhysopaussini and Falsocossyphini (Coleoptera; Tenebrionidae). Mitteilungen der Münchner Entomologischen Gesellschaft 104 : 3-176.

FAIRMAIRE L. 1892: Nouveau genre de Coléoptère hétéromère. Bulletin de la Société Entomologique de France 61: CX-CXI.

GEBIEN H. 1943: Katalog der Tenebrioniden. Mitteilungen der Münchner Entomologischen Gesellschaft 33: 895-926.

HOZAWA S. 1914: Note on a new termitophilous Coleoptera found in Formosa (Ziaelas formosanus). Annontationes Zoologicae Japonenses 8: 484-488.

MASUMOTO K., LEE C.-F. \& AKITA K. 2016: A note of the genus Ziaelas (Coleoptera, Tenebrionidae, Amarygmini) with a description of a new species from the southern part of Vietnam. Japanese Journal of Systematic Entomology 22: 209-213.

WASMANN E. 1896: Neue Termitophilen und Termiten aus Indien, IV (Nachtrag). Annali del Museo Civico di Storia Naturale di Genova (Serie 2) 17: 149-152.

WASMANN E. 1912: Zwei neue Paussiden und ein neuer Rysopaussine aus niederländisch Indien. Tijdschrift voor Entomologie 55: 255-262. 
